\title{
Erratum to: Effect of rs6983267 polymorphism in the 8q24 region and rs4444903 polymorphism in EGF gene on the risk of sporadic colorectal cancer in Iranian population
}

\author{
A. Daraei • R. Salehi • M. Salehi • M. H. Emami • \\ M. Janghorbani $\cdot$ F. Mohamadhashem • \\ H. Tavakoli
}

Published online: 12 August 2011

(C) Springer Science+Business Media, LLC 2011

Erratum to: Med Oncol (2011)

DOI 10.1007/s12032-011-9980-2

Unfortunately the fifth author of the article was listed incorrectly in the original version. The correct name of the fifth author is M. Janghorbani (not M. Jonghorbani).

The online version of the original article can be found under doi:10.1007/s12032-011-9980-2.

\footnotetext{
A. Daraei · R. Salehi $(\bowtie) \cdot$ M. Salehi $\cdot$ F. Mohamadhashem Department of Biomedical Sciences, School of Medicine, Isfahan University of Medical Sciences, Isfahan, Iran

e-mail: r_salehi@med.mui.ac.ir

M. H. Emami · H. Tavakoli

Isfahan University of Medical Sciences, Isfahan, Iran

M. H. Emami · H. Tavakoli

Poursina Hakim Research Institute, Isfahan, Iran

M. Janghorbani

Department of Epidemiology and Biostatistics, School of Public

Health, Isfahan University of Medical Sciences, Isfahan, Iran
} 